\title{
Development Support Communication: Problems and Suggestions
}

Aamir Shahzad ${ }^{1^{*}}$ and Bokhari SA ${ }^{2}$

M. Phil. scholar, Islamia University of Bahawalpur, Pakistan

PhD scholar, GOML University D-I khan Pakistan

Corresponding author: Shahzad A, M. Phil. scholar, Islamia University of Bahawalpur, Pakistan, Tel: 0092-321559655; E mail: amir.mphil@yahoo.com

Rec date: Feb 27, 2014; Acc date: May 08, 2014; Pub date: May 15, 2014

Copyright: ( 2014 Shahzad A, et al. This is an open-access article distributed under the terms of the Creative Commons Attribution License, which permits unrestricted use, distribution, and reproduction in any medium, provided the original author and source are credited.

\begin{abstract}
:
The purpose of this paper is to provide an overview of the concept of Development Support Communication (DSC), its beginning, features and emerging trends. This paper focuses on the evaluation and emergence of concept DSC and related terms. This study also tries to highlight the problems in successful DSC programs in general and particularly in Pakistan. Concluding this paper, suggestions for successful DSC programs are given by focusing on community participation (social organizations, interpersonal, traditional modes) and media.
\end{abstract}

Keywords: Development; Communication; Development journalism (DJ); Development communication (DC); Development support communication (DSC); Dominant paradigm; Alternative paradigm; Community development; Mass media; Community participation

\section{Introduction}

The term Development is heavily loaded with different conceptions and a richness of uses and functions shaped by their various theoretical foundations. The term development for communication can be defined as "It is a process through which a society is expected to achieve certain socio-economic, political, cultural and other goals".

Todar and Smith [1] identified three objectives of development as follows:

- To increase the availability and widen the distribution of basic life sustaining goods such as food, shelter, health and protection.

- To raise levels of living in addition to higher incomes, the provision of more jobs, better education, and greater attention to cultural and human values, all of which will serve not only enhance material well-being but also to generate greater individual and national self-esteem.

- To expand the range of economic and social choices available to individuals and nations by freeing them from servitude and dependence, not only in relation to other people and nation-states but also to the forces of ignorance and human misery.

\section{Objectives of the Study}

The specific objectives of the research paper are outlined as below:

- To discuss the emergence and importance of (DSC).

- To highlight the problems and issues in DSC.

- To suggest the solution.

\section{Procedure of the Study}

This is a review paper and the data was collected from books, research articles and from the internet.

\section{Emergence and Importance of DSC}

Development is a concept which is as old as the human history itself. In 18th century industrial revolution in Europe-World War I and II gave new dimensions to this concept. Focus on increase in percapita income, agriculture and Industrial productions, There emerge a new concept of "development as a total change" as positive change in life conditions, traditional social culture setup attitudes and behaviors.

Under contemplation of Development "Communication is an omnipresent human activity carries information about ideas, things, places, persons and policies. Through which a human being understands other and in return is understood by others".

By Understands events; gets informed and takes well considered decisions that Provides new venues to accept or reject what is good and what is not. But its relevancy with mass communication, the word communication belongs to the Latin and Greek Words "Communis" and "Communicane" - both stands for "to make something common between two or many people".

Moreover Carl Hovland defines [2,3], "Communication is the process by which an individual (the communicator) transmits stimuli (usually verbal symbols) to modify the behavior of other individuals (communicatees).

After the destruction brought about by the Second World War, there a question was raised for the development in the Western Countries. Poverty and economic crisis in the third world countries, Lack of science, technology, technical sufficiency in third world countries and Unavailability of investment facilities and lack of saving due to poverty, at that time in third world countries, grounded the idea that if western countries want to develop themselves, it is necessary that the third world countries should also be given facilities to develop, so they no longer suffer from economic crisis.

Thus concept of development communication (DC) [4] arose within the framework of the contribution that communication and the media made to development in the countries of the Third World. Development communications are organized efforts to use communications processes and media to bring social and economic improvements, generally in developing countries. Three main ideas which define the philosophy of development communication and 
make it different from general communication are: Development communication is purposive communication, it is value-laden; and it is pragmatic. In the development context, a tacit positive value is attached to what one communicates about, which shall motivate the people for social change $[5,6]$.

But originally the term Development Communication (DC) was used by the Western writers like Daniel Lerner, Lucian Pye and Wilbur Schramm $[7,8]$. Taking the sense into consideration, Nora C. Quebral [9] says, that "Development communication is an art and science of human communication apply to the speedy transformation of a country and mass of its people from poverty to a dynamic state and the larger fulfillment of the human potential." It is a technology based communication network, Regardless of message and content it tended to create, by reason of its inherent characteristics, a climate suited for development.

\section{Characteristic of DS:}

- Large universe.

- National development at macro level.

- Without specific development goal.

- Open ended and persuasive (with time limit)

- Limited to mass media.

- Functions from top to down.

- Wide range of variables, difficult to control.

- No feedback.

- No interpersonal communication.

- Lost its credibility.

(Development Support Communication, Study Guide, AIOU.) [10]

Initially there was the concept of Development Communication (DC) in whole world but after world war devastation in field of social, cultural and economic, DS was in the mod of transformation as The United Nation, World Bank and different NGOs were established to solve the problems after the world war. During 1950s loans were issued to under develop countries and technology was transferred to speed up their development process. After a decade when analysis was done, it was realized that most of the plans failed. Projects were wasted and the problems of the people living in the rural and urban areas remain unsolved. Factors lying behind the failure of these projects were lack of understanding about social and cultural environmental problems, and lack of interpersonal communication of project developers. They were unable to create a strategy to make successful plans. They couldn't involve farmers, poor, semi illiterate people to participate in decision making process for their own benefit. Then it was realized that one country's development strategy cannot be applied over another country, it s better to plan projects in the light of the needs of that area, climate, thinking, concepts, culture, tradition, and the aptitude of the local people.

Thus In this situation in early 1960s the idea of development support communication (DSC) was conceived by Professional Information Officer Erskine Childers. He was employ of the United Nations Development Program (UNDP). Childers proposed that the planners and projects developers can't enforce and motivate the people towards successful development and change. He suggested that this job can be well managed only by the people who know the art of communication. This idea leads to the concept of "Development Support Communication (DSC)".
Childers proposed a receiver oriented approach to development communication which would render communication as a "support" rather than a deterrent to development. It quickly gained prevalence in UNO and other multilateral development agencies.

\section{Erskine Childers, according to him}

"DSC is specifically designed communication strategies which support a particular development program". In general, "DSC is a concept of communication activities that undertake exchange of messages at more participatory level to achieve specific goals of exchange and development."

In the view of Rogers [11]: "Development communication refers to the uses of which communication is put in order to further development. Such applications are intended to either further development in a general way, such as by increasing the level of the mass media exposure among nation's citizens, in order to create a favorable "climate' for development, or to support a specific development programme or project this type of development communication is often termed as Development Support Communication."

\section{The Philosophy of DSC}

- The latest efforts undertaken to bring about a change in a limited area.

- It emerged as a more specific and participatory communication effort to educate the people of rural settings.

- It aims at targeting the audience to achieve a specific and defined goal of change and development.

- It does not depend on technological based communication media.

- It works within a limited community to create awareness about innovations.

- Its philosophy is to motivate the intended audience towards change using all available means of communication.

- It interacts more closely.

\section{Development Communication Paradigms}

\section{Dominant paradigm of development}

The dominant paradigm of development came into being in the 1960s based on the idea of modernization (industrial revolution, capital-intensive technology, economic growth and quantification per capita income index). Change agents of interpersonal system, together with the multiplying mass media are the twin pillars of the dominant paradigm, to introduce new ideas and practice in a given social system. Communication in the Dominant Paradigm became the crucial instrument of the directed social change [12] initiated and instigated by outsiders representing programmes of planned change.

It is the strategy of communication which flows from top to down. Development planner at the "Top" and relay "down" by technical assistance, intermediaries through government's beneficiary for implementation by using mass media and interpersonal communication.

The powerful effect characterization is known as "hypodermic needle" theory; the "bullet and mechanistic S-R Theory" has largely been assumed in the dominant paradigm. 


\section{The paradigm puts heavy emphasis on}

- Investments in the "Modern" sector with the hope that it would trickle down the advantages to the traditional setting.

- The existence of a free enterprise system giving transnational corporations to access to both raw materials and sale on the commercial market.

- Importation of advanced capital intensive technology by the developing countries.

- Stimulation of saving by preserving income gaps, particularly in the developing countries, the assumption that equalization leads to less savings(= less money for investment).

- Development aid in the form of loans, gifts technical assistance, and trained personnel.

\section{Alternative paradigm}

The alternative paradigm evolved during 1960s and 1970s due the critical reasons like capital world order, unequal distribution, stress on economic development and top-down communication. Under the dominant paradigm social and economic development imposed upon the third world countries, resulted in an alienation of people from their original and natural potentials. Consequently the third world countries started thinking for the proper utilization of all their energies, the manpower delineation of human being, restoration of dignity, self-respect and faith in one's own capabilities.

This trend led social and economic scientist of the third world to search a new model or paradigm for development that can work proper. Then the idea of alternative paradigm emerged in concept of development. China, Tanzania and Cuba gave this idea on the basis of some international events and issues world oil crisis, realization of third world and relations with china.

Alternative paradigm is based upon these points:

- It is the strategy of communication which flows from down to top meaning starting from the grass root level.

- Use of local natural resources usefully.

- Use of human resources usefully and making few alternative opportunity of work power into appropriate labor.

- Use of existing knowledge and dissemination of mass education in society or in whole country.

- Spreading the innovations (new technology) equally to everyone.

- Increasing more jobs opportunities in rural areas.

- Promotion of idea of cooperation, "let's work together".

- Equal distribution of wealth, education, technology, health facilities by closing the gap between haves and have-nots.

- Make the society homogeneous (social, cultural and economic).

- Making small groups of community and giving them tasks to complete.

- Focusing on integration of modern system with traditional, social, cultural values (marriage of traditional system with modern one).

- Involvement of every person of society in making policies and planning their own system for development and betterment.

- Equal use of media for all segments in society.

- Systematic network of Interpersonal communication.

- Involvement of opinion leaders.

- Dissemination of innovative messages.

- Use of traditional media especially radio.

\section{DSC and change}

The concept of change is positive in character which leads and motivates human beings towards better living conditions. Change process may occur at various levels and in different form. It may be termed as a change in people's physical structure, change in technology, social organization, normative values, demographic characteristics, agriculture, health and education etc. To our specific purpose, levels of change are summarized as:

Urbanization: The condition of being urbanized - it refers to increasing number of people that live in urban area.

Industrialization: The development of industry on an extensive scale - The process in which a society or country (or world) transforms itself from a primarily agricultural society into one based on the manufacturing of goods and services.

Modernization: Making modern in appearance or behavior - to accept or adopt modern ways, ideas or styles.

In DSC context, sources of change are integral to the nature and importance of an intended change.

\section{Sources of change}

Land: A basic source of change, particularly in an agriculture community.

Work Force: Human beings-their intentions, interests and abilities.

Capital: Its availability, procurement and proper utilization.

No change strategy can accomplish its goals without financial support which obviously needs capital.

Education: Leads a community towards awareness of what to do, what to accept and what to reject or modify. Change efforts can hardly succeed without educating the target society / community.

Opinion leaders: Such as social workers, local religious leaders (Imams in our society), school teachers etc.

Media Channels: Especially interpersonal communication in village settings.

Professionals: Professionals are associated with institutionalized arrangements for carrying on change actions. They may be attached with different social communities agencies, such as health and family planning programs. They may also be communication experts.

Transport facilities: An important source of change in any community / society. Road, railways and other means of transportation link the change and reach the target areas. As change need flow of goods, ideas and essential mobility of human beings.

Government: Its structure, leadership, direction, planning and ability to execute the change projects.

Socio-cultural Values, belief system: In any change process, these components play decisive role of accepting and accommodating new ideas and things, of rejecting or resisting anything coming from outside.

But many campaigns and projects of DSC and change have been failed because assumptions were made about the willingness and capacity of people to absorb new technology and development infrastructures into their way of living and working. In third world 
countries especially in Pakistan DSC programs are facing some other obstacle in successful DSC.

As philosophy behind DSC is to formulate and apply communication strategies specifically designed for concrete development program. It is generally used in micro situations. Concepts such as diffusion of innovations, two-step-flow and change agents are more easily operationalized under DSC.

\section{Problems in successful DSC program}

- Lack of Finance

- Lack of self-reliance in terms of money

- Misuse of funds

- Lack of planning

- Lack of investment

- Lack of education

- Lack of professional training

- Lack of use of modern communication means

- Lack of use of modern transportation

- Control over media

- Lack of government interest

- Administrative problems

- Lack of highly educated \& skilled people

- Socio-cultural problems (diversities in language, customs, traditions and religions)

- Lack of youth \& female participation

- Corruption

- Poverty

- Foreign pressure

- Wrong planning

- Lack of involvement of local people

- Lack of foreign investment

- Lack of cultural imperialism

- High rate of population growth

- Lack of use of natural resources

- Misleading identification of the problems

- Self-interest of bureaucracy

- Messy infrastructure of national institutions

- Lack of media guidance

- Lack of youth development programs.

- Lack of political \& provincial integration

- Lack of DSC awareness

Development communication is characterized by conceptual flexibility and diversity of communication techniques used to address the problem. Some approaches in the "tool kit" of the field include: information dissemination and education, behavior change, social marketing, social mobilization, media advocacy, communication for social change [11], and participatory development communication.

To bring about change and to overcome the problems in DSC, there is a solution of community participation on the basis of which real change can occur which will base on the needs and demands of public.

\section{Participatory Approach}

The reaction against modernization (and to some extent the realization of global structural imbalances) gave birth to participatory approach basis on actively involving people who were the "subjects" of development in happening of the process.

The roots of participatory approaches in development communication can be found in the early years of the 1970s when many people in the development community began to question the top-down approach of development dominant in the 1950s and 60s which had targeted the economic growth of countries as its main goal. During these two decades the success of the developed countries was held-up as the model to aspire to. Development was thought to be triggered by the wide-scale diffusion and adoption of modern technologies. Such modernization was planned in the national capitals under the guidance and direction of experts brought-in from developed countries.

The overall approach to modernizing the developing world eventually ran into problems. It was realized that development was not restricted to just building roads, piping water, and distributing electricity. Nor was it limited to neither increasing farm yields per hectare nor switching farmers over to cash crops.

Over-riding the alien information communicated to the people was a bigger problem. Because the development had been centrally planned without any consultation with people, wrong solutions were often pumped down to startled communities.

The expensive failures of the top-down, mechanistic approach were noticed in the cities. Activists began to loudly criticize them as focused on the symptoms, not root causes of poverty. They were appalled by the arrogant top-down communication which fractured fragile developing communities by under-mining indigenous knowledge, beliefs and social systems. They were also furious with development plans which catered more to the interests of the city elites than the people in the villages.

\section{Interpersonal Communication}

Just as during the modernization era, communicators responded to the shift towards participation in development by echoing the new approaches. To compound the challenge, much of the seminal thinking ha $\mathrm{d}$ focused on interpersonal processes. Also, for the first time development communication was no longer in the exclusive domain of the professionals. Participatory communication, in the ideal situation, is practiced spontaneously by the people without mediation. It was ideally the by-product of participatory processes and participatory communities.

The emphasis on interpersonal and traditional methods encouraged the development and use of these communication methods which had been largely ignored until then. Street theatre, folk-songs, speech, and group activities became important and effective channels for participatory communication. Large scale national communication activities were set aside in favor of small, localized and intimate programs.

The stress on interpersonal approaches at first suggested a smallscale, community -based approach to participatory communication. Speech, traditional and folk media, and group activities were considered the most appropriate instruments for supporting the approach. Community radio scored some of the early successes. The large, centralized model of the city-based station was replaced by small operations broadcasting on low-power transmitters owned by trade unions, churches and other communities. The people produced and voiced the programs which were focused on local issues which were 
the most current and important to them. Such innovations made way for participatory communication to be practiced at both the community or village level and at the broader regional or sub-regional level.

According to Uphoff cited in people of the community can be involved in development in four ways:

Participation in implementation: People should actively encourage and mobilized to take part in the actualization of projects. They should give certain responsibilities and set certain tasks or required to contribute specified resources.

Participation in evaluation: Upon completion of a project, people should invite to critique the success or failure of it.

Participation in benefit: People should take part in enjoying the fruits of a project, this maybe water from a hand-pump, medical care by a "bare-foot doctor", a truck to transport produce to market, or village meetings in the new community hall.

Participation in decision-making: People initiate, discuss, conceptualize and plan activities they will all do as a community. Some of this may be related to more common development areas such as building schools or applying for land tenure. Others may be more political, such as removing corrupt officials, supporting parliamentary candidates, or resisting pressures from the elites. Yet others may be cultural or religious in nature--organizing a traditional feast, prayers for an end to the drought, and a big party just to have a good time. In all matters people living in any community should have proper rights to participate in decision making.

\section{Planning DSC campaign}

Planning is supposed to be a prerequisite of any programme. In case of Development Support Communication (DSC) and community participation, appropriate planning is the primary step for achieving the goals. DSC campaign: it is an integrated manner that utilizes different educational and communication methods, aimed at focusing attention on a particular problem and its solution over a period of time.

\section{Creating the plan}

There are three stages of any DSC Campaign plan.

Stage 1: Identification of objectives

Stage 2: Analysis (analysis of a problem, target audience, situation \& sponsor)

Stage 3: Formulation of the plan (selection of the suitable method, timing the campaign, using slogans and symbols, pretesting the messages, providing channels for information seeking \& involving people).

Keeping in view the importance and workability of community participation, community media can play a vital role to reduce and eradicate the problems and issues in DSC. Certain methodology for activating the community media can brighten the pave towards success if the focus is on these points.

- Identification of needs by means of direct contacts with the groups;

- Concretization: examination of the problem identified by the groups in the light of local conditions;
- Selection of priority problems by the groups;

- Formulation of a durable methodology for seeking solutions;

- Identification of the amount of information required and access to this information;

- Action: execution by the groups of the projects they have designed;

- Expansion toward the outside to make known the points of view of the groups to other groups or to the authorities;

- Liaison with the communication system to make known their action.

(Berrigan) [13].

\section{Using Mass Media for DSC}

Although interpersonal communication is the main tool of DSC operation, however, personal or face-to-face methods cannot reach everyone who wants and needs information. So following mass media methods are used to reach large numbers of people quickly.

- Print media (newspapers, wall newspapers, blackboard news, newsletters, folders, leaflets, pamphlets, and factsheets)

- Audio visual media (radio, audio cassette, TV, pictures, slides, film strips, overhead transparencies \& audio visual recorder)

- Static media (posters, exhibits and displays)

- Emerging technology (communication satellites, telephones, video conferences, FM radios, 3D graphics, multimedia projectors, CDs, DVDs, Mobile phones and mother of all "the computer \& internet")

These methods are particularly useful in making large number of people aware of new ideas and practices, or alerting them to sudden emergencies. While the amount of detailed information that can be transmitted by mass media is limited, they will serve an important and valuable function in stimulating target audience interest in new ideas. Once stimulated or made aware through mass media, audiences will seek additional information from neighbors, friends, extension workers or progressive audiences in the area.

\section{Discussion}

During the past two decades the purposeful application of media and communication support has assumed an increasingly important role in many facets of development.

Broadly defined by the U.S. AID, the process refers to "The application of existing communication technologies and media to the problems of development". FAO more precisely delimits DSC as "The systematic utilization of appropriate communication channels and techniques to Increase people's participation in development and to inform, motivate, and train rural populations, mainly at the grassroots level".

The idea of using media to assist Third-World development grew out of relatively consistent research findings demonstrating that focused, receiver oriented communication strategies could play a significant role in accelerating the rate of technology transfer, whether it be process or product - or both. Thus, as communication technologies improved, became easier to use, and costs lowered, broadcasting and a variety of "small media" were increasingly harnessed to reach people at the village level.

Prior to this, the main vehicle for linking scientific advances in agriculture, health and nutrition between researchers and rural 
adopters was the extension worker. Historically, however, their singular efforts have been limited by the thin spread of front line agents available in relation to the volume of people requiring information and training. Transportation difficulties have also tended to impede their outreach.

In addition, effective communication with predominantly illiterate farmers was hampered by poor training in face-to-face communication techniques. Against this background, the use of media could accelerate awareness of, and adoption rates toward, recommended technologies through targeted information, motivational messages and training.

Nowadays development, it is common to talk about media categories which are taken to include broadcast (television and especially radio), group (video, tape-slides, sound film-strips, audiocassettes, overhead projections, flip-charts, posters, pamphlets, and leaflets; as well, traditional folk media such as puppets and live-theatre may be included), and Interpersonal channels (community leaders, contact farmers, extension workers). And DSC delivery strategies have been hierarchically ranked, in terms of complexity, from interpersonal communication through radio and television broadcasting, and group media, to multi-channel campaigns. This ranking also subsumes the notion that each strategy can be made more effective by incorporating that which precedes it. Radio broadcasts, for example, have much more impact if they are backstopped with authoritative, village based interpersonal sources, and group media can benefit from both radio and interpersonal communication support. Well-designed communication campaigns usually involve broadcasting; village based group media, and intensively trained field workers. The general rule of thumb emerging from two decades of field experience is to use multiple channels, wherever possible, so that each medium reinforces and multiplies the importance of the others in an integrated network.

\section{Suggestions}

\section{To make DSC successful}

- Understanding the target audience their problems and solution to the problems.

- In-depth socio-cultural study of a given community in order to produce consistent message contents.

- Keeping men, messages and means free from constraints imposed by any authority.

- Proper training and communication skills for DSC operators.

- Full participation of community members, especially the community leaders.

- DSC form within the rural communities.

- Incentives for local media, particularly community newspapers, local radio stations etc, if available.

- Artificial urban oriented message system creates vacuum-gap between the communicator and the audience. It should be avoided.
- Use the appropriate means of communication for DSC.

\section{Conclusion}

Development communication is not merely concerned with providing information on development activities. Besides creating opportunity for the people to know about the technical nature of new ideas and on how they work and with what effect, development communication plays the more important role of creating an atmosphere for understanding how these new ideas fit into the real social situation in which the people operate. Its ultimate goal is to catalyze local development activities, local development planning and implementation, and local communication to smoothen the path to development. Youth and women participation should make possible. Communication here should not stop with conventional mass media. If development communication must succeed, then it must include strong components of social organization and interpersonal as well as traditional modes and media. In addition, those in charge of planning development communication must be those who understand the social structure (those who have entered into the socio-cultural contexts of the people) and how change can take place in it, not merely how development messages can be disseminated.

\section{References}

1. Todaro M, Smith SC (2003) Economic Development (8th edition). India: Pearson Education (Singapore) Pte. Ltd. Indian Branch.

2. Baran Dennis K, Davis (2009). Mass communication theory: foundations, ferment, and future (6th edn). Boston, MA: Wadsworth.

3. Baran SJ (2009) Introduction to mass communication: Media Literacy and Culture (3rd edn). New York: McGraw-Hill.

4. Narula U (1994) Development Communication, Haranand Publication, New Delhi.

5. Servaes J (1992) Participatory Communication for Social Change. Development Communication Report.

6. Servaes J (1996) Participatory Communication Research with New Social Movements: A Realistic Utopia. Participatory Communication for Social Change, New Delhi: Sage.

7. Lerner D, Schramm W (1967) Communication and Change in the Developing Countries. East West Center Press.

8. Schramm W (1964) Mass Media and National Development. Stanford: Stanford University Press.

9. Quebral, Nora C (1973) What Do We Mean by Development Communication? International Development Review 15: 25-28.

10. Development Support Communication (2009) Development.

11. Rogers EM (1976) Communication and Development: The Passing of the Dominant Paradigm. Communication and Development: Critical Perspectives, Beverly Hills: Sage Publications.

12. Gumucio-Dagron A, Thomas $\mathrm{T}$ (2006) Communication for Social Change. Anthology: Historical and Contemporary Readings. CFSC Consortium.

13. Berrigan FJ (1981) Community Media and Development. Paris: UNESCO. 